\title{
El régimen jurídico de las empresas industriales y/o comerciales del Estado, ¿derecho administrativo o derecho económico?
}

\author{
The legal regime of the industrial and commercial \\ companies of the State, administrative law, \\ or economic law?
}

\section{Carlos Ferney Forero Hernández}

Magíster en Derecho Administrativo.

\begin{abstract}
Aspirante a doctor en Derecho Público, Universidad Santo Tomás -Tunja, Colombia
Director del Semillero de Investigación de Derecho Administrativo

"Jaime Vidal Perdomo", Programa de Derecho, Universidad de Ibagué. Integrante del Grupo de Estudios de Derecho Penal Económico, GEDPE,

Universidad de lbagué.

carlos.hernandez@unibague.edu.co
\end{abstract}

\section{Resumen}

En la academia se ha discutido con frecuencia respecto de si el régimen jurídico de las empresas industriales o comerciales del Estado es derecho administrativo; algunos consideran que no lo es, en la medida en que estas empresas son creadas como modalidades de intervención del Estado en la economía y, por ende, correspondería con el derecho económico, mientras que otros consideran que es derecho administrativo, por formar parte del campo de estudio de la rama ejecutiva del poder público. De esta manera, el objeto de este texto es diferenciar a la 
comunidad académica sobre la conveniencia de hablar de derecho económico, y no de derecho administrativo, cuando hacemos referencia al régimen jurídico de las empresas industriales y/o comerciales del Estado. Entendiendo por derecho económico como el derecho de la dirección e intervención del Estado en la economía. Aceptar que su régimen es derecho económico implica aplicar el Análisis Económico del Derecho (AED) que es una herramienta que propende por la eficiencia en las actividades económicas. Este tema tiene un enfoque interdisciplinar que vincula el derecho y la economía.

\section{Palabras clave}

Empresas industriales y/o comerciales del Estado; derecho económico; derecho administrativo; análisis económico del derecho - AED.

\section{Abstract}

Academia frequently discussed whether the legal regime of industrial or commercial companies of the State is administrative law; some consider it is not, because these companies are modalities of the intervention of the State in the economy and, therefore, it would correspond to economic law. Others consider it to be administrative law since it is part of the field of study of the executive branch of public power. In this way, the purpose of this text is to differentiate the academic community on the convenience of talking about economic law, and not administrative law, when we refer to the legal regime of industrial or commercial companies of the State. Understanding by economic law as the right of the direction and intervention of the State in the economy. Accepting that its regime is economic law implies applying the Economic Analysis of Law (EAL) as a tool that aims for efficiency in economic activities. This topic has an interdisciplinary approach that links law and economics.

\section{Keywords}

Industrial or commercial companies of the State, economic law, administrative law, Economic Analysis of Law-EAL.

Cómo citar este artículo:

Forero Hernández, C. (2021). El régimen jurídico de las empresas industriales y/o comerciales del Estado, ¿derecho administrativo o derecho económico? Revista de la Facultad de Derecho y Ciencias Políticas, 51 (134), pp. $52-82$.

doi: https://doi.org/10.18566/rfdcp.v51n134.a03

Recibido: 01 de abril de 2020

Aprobado: 10 de septiembre de 2020 


\section{Introducción}

Del régimen jurídico de las empresas industriales o comerciales del Estado es muy común afirmar que, al formar parte del campo de estudio de la rama ejecutiva del poder público, es de derecho administrativo (Rodríguez, 2012). El derecho administrativo se identifica como el derecho de la función administrativa (Montaña, 2010). Otros afirman que es derecho público en la medida en que su creación se da por virtud de la voluntad del Estado, cuyo fin se radica en la consecución del interés general y eso es derecho público (Younes, 2016). De esta manera, el problema por resolver es el siguiente: iel régimen jurídico de las empresas industriales o comerciales del Estado se enmarca en el derecho administrativo?

En este texto se considera que el régimen jurídico de dichas empresas, por la evidente realización de actividades económicas para el logro de la estabilidad socioeconómica del país -vista como modalidad de intervención del Estado en la economía (Constitución Política, 1991, Artículo 334)-, es de derecho económico. Entendiendo este último como el derecho de dirección e intervención del Estado en la economía. Al ser parte del derecho económico resulta entonces aplicable el análisis económico del derecho, AED, herramienta que permite estudiar las instituciones jurídicas con criterios económicos (Forero, 2019), y que propende por la eficiencia en las actividades económicas.

De esta manera, las líneas que siguen pretenden analizar la conveniencia de la alusión al derecho económico, y no al derecho administrativo, cuando se hace referencia al régimen jurídico de las empresas industriales o comerciales del Estado. Para esto, se propone el siguiente acercamiento al tema: a) nociones de derecho económico y derecho administrativo. Ubicación del tema; b) el régimen jurídico de las empresas industriales o comerciales del Estado. Aspectos generales; y c) ies de derecho administrativo el régimen jurídico de las empresas industriales o comerciales del Estado?

\section{Método}

Se trata de una investigación con enfoque cualitativo. Por esta razón, este texto explica y profundiza algunas nociones básicas del derecho administrativo, del económico y del régimen jurídico de las empresas industriales o comerciales del Estado. Se elige un diseño secuencial, comienza con el proceso de recolección y estudio de información cualitativa consistente en la revisión 
de libros, artículos de investigación y reflexión. Una vez conocida las nociones de derecho administrativo y derecho económico se analizan cuál es el régimen jurídico aplicable a las empresas industriales o comerciales del Estado. En este texto se propende por la conveniencia de hablar de derecho económico, y no de derecho administrativo, cuando nos referimos al régimen jurídico de las empresas industriales o comerciales del Estado, lo que, desde la perspectiva propuesta, propende a un mejor estudio, a un análisis de manera coherente.

\section{Justificación}

La justificación de revisión doctrinal y legal respecto del régimen jurídico de las empresas industriales o comerciales del Estado se radica en contribuir a un mejor estudio, así como de un adecuado análisis en la comprensión del régimen jurídico de dichas empresas, específicamente al hablar de la rama ejecutiva del poder público. De ahí que aceptar que su régimen es derecho económico implica la aplicación del análisis económico del derecho (AED), que es una herramienta que propende por la eficiencia en las actividades económicas de dichas empresas.

\section{Resultados}

\section{Las nociones de derecho administrativo y derecho económico. Contextualización}

Los estudiosos de la teoría general del derecho, así como de la filosofía del derecho, han resaltado que la tarea de elaborar una noción exacta de derecho no ha sido fácil. Siempre se han generado, y se seguirán generando, dificultades. En la literatura se encuentran varias teorías que nos permiten construir la noción de derecho como las identificadas y explicadas por Norberto Bobbio (1987): a) normativista (el derecho es un sistema de normas jurídicas); b) institucionalista (el derecho es el producto de la sumatoria de orden social y sociedad); c) relación jurídica (el derecho es una relación jurídica) y d) estatalista (el derecho es el Estado).

En la que más profundizó Bobbio (1987) es la teoría estatalista, y se debe a que el Estado es el titular del monopolio en la producción de normas jurídicas, y eso es derecho, desde dicha perspectiva. Algunos estudiosos apoyan la primera teoría, es decir, la normativista, en la medida en que en ella orienta a las demás. 
Este texto se inclina a que el derecho se debe identificar como un sistema de normas jurídicas. Tiene por objeto el estudio de las normas jurídicas vigentes. No obstante, se encuentran numerosos artículos que resaltan que la teoría más aplicada para la construcción de la noción del derecho es la institucionalista, resaltando el papel de las instituciones formales (todas las normas jurídicas) e informales (normas de conductas impuestas por convenciones), que es tema principal de la nueva economía institucional, NEI (Pinzón, 2016).

En la NEI, como nuevo paradigma dentro del derecho económico, se estudia con frecuencia, al igual que el análisis económico del derecho - AED, la intervención y dirección por parte del Estado en los procesos económicos (o en el mercado, para algunos) en caso de disfuncionalidades o fallas. Tal intervención y dirección en la economía cuenta con el respaldo constitucional que se encuentra en el Artículo 334 de la Constitución Política de 1991, donde se resalta que el Estado interviene en la economía para mantener y preservar el orden público económico.

Respecto de la división del derecho en público y privado, son pocos los libros que giran en torno a esta justificación. De hecho, profundiza más en la clasificación del derecho que en la división del mismo. De ahí que clasificación y división no son la misma cosa, esto hay que advertirlo. Al revisar varios libros de introducción al derecho se da a entender que, para algunos estudiosos, tal división es inútil para su análisis. Este texto se considera útil, pues permite determinar la aplicación de normas jurídicas de manera coherente a ciertos actos o hechos jurídicos. Claro está que tal división no está exenta de críticas, porque hay escenarios en los que se aplican, al mismo tiempo, el derecho público y el derecho privado, como se demostrará más adelante; esta es una de las dificultades identificadas por los teóricos del derecho al hablar de la división de esta disciplina.

Se señala, primero, que la división del derecho público y derecho privado tiene su origen en el derecho romano, tal como lo identifica Medellín Forero (2013). Una de las fuentes del derecho corresponde al Corpus Iuris Civiles de Justiniano y en él se encuentran el digesto, las instituciones y las novelas. En el primero, el digesto, se clasificó (utiliza el término clasificación) el derecho en derecho público y privado. Es de precisar que tal separación se debe al trabajo del jurista Ulpiano (Quintana, 2004). Con el paso del tiempo, los alemanes consideran que esta teoría (de división) no es de recibo, por cuanto el derecho es, y será, uno (o único). 
Es pertinente señalar cuáles son las ramas del derecho público, y cuáles aquellas del derecho privado, para luego preguntarnos si existe un derecho mixto. El derecho público es aquel que se ocupa de los asuntos del Estado. En cambio, el derecho privado se enfoca en los asuntos de los particulares. A simple vista, esta explicación resulta comprensible, claro está que es factible de ser criticada en la medida en que, por ejemplo, en la contratación estatal, que es uno de los asuntos del Estado que es de derecho público, se aplican también -y con mayor rigor- normas de derecho privado (Forero, 2020a)

En el derecho público se encuentran, como ramas el derecho constitucional, el derecho administrativo, el penal, el procesal, el internacional público, entre otros. En el derecho privado se comprenden el derecho comercial, el civil, el derecho de familia, el derecho laboral, el derecho internacional privado, entre otras. Frente a esta explicación se comparten las explicaciones ofrecidas por Marín Cortés (2008) al señalar que la dicotomía derecho público y derecho privado implica tres situaciones. La primera indica que tal división permite estudiar sobre una sociedad de iguales (relaciones entre particulares) y sociedades desiguales (relaciones entre Estado y particulares, estos últimos subordinan al primero). La primera explicación se identifica con el derecho privado; en cambio, la segunda, con el derecho público.

La segunda situación alude al estudio de la Ley y contrato. La Ley se identifica con el derecho público en la medida en que esta no puede ser derogada por los particulares. El contrato es el producto de la autonomía de la voluntad de las partes que es propia del derecho privado, celebrado entre particulares (se debe tener en cuenta que el Estado puede celebrar contratos). Y, finalmente, se estudia la justicia conmutativa y distributiva; la primera es de derecho privado, en cambio, la segunda, justicia distributiva, es de derecho público (es su propósito, teóricamente hablando).

En relación con la división del derecho en público y privado surge este interrogante: ¿existe un derecho mixto? Son pocos los libros que aluden al derecho mixto en virtud del derecho público y privado. En este texto se considera que sí existe un derecho mixto, miremos varios ejemplos. El régimen jurídico de los actos administrativos es un derecho mixto, porque se aplican al mismo tiempo normas de derecho privado, tales como la teoría del acto jurídico, de la personalidad jurídica, de los derechos adquiridos, así como normas de derecho público, como la aplicación de principios de la función administrativa señalados en el Artículo 209 de la Constitución Política de Colombia: moralidad, eficacia, economía, publicidad, igualdad, imparcialidad, etc. 
El derecho tributario es un derecho mixto, porque se aplican igualmente, y al mismo tiempo, normas de derecho privado tales como, entre otros, modos de extinguir las obligaciones como el pago, prescripción, compensación, etc., así como normas de derecho público, como los principios constitucionales del sistema tributario señalados en el Artículo 363 de la Constitución Política colombiana: equidad, progresividad, irretroactividad y eficiencia (Forero, 2019). El objeto de estudio del derecho tributario es el tributo, como uno de los ingresos públicos para el financiamiento del gasto público (Constitución Política, 1991, Artículo 95).

Desde lo jurídico, la contratación estatal también es un derecho mixto, porque se aplican con mayor rigor normas del derecho privado (principalmente normas de derecho comercial y civil) tales como la teoría del acto jurídico, de la autonomía de la voluntad de las partes, la buena fe contractual, etc., así como normas de derecho público como los principios de la función administrativa y de la gestión fiscal, señalados en su orden en los artículos 209 y 267 constitucionales.

El régimen jurídico de la responsabilidad patrimonial del Estado es también un derecho mixto, por cuanto aplica normas de derecho civil como los perjuicios materiales e inmateriales, responsabilidad por el hecho propio (responsabilidad directa), las causales de exoneración (caso fortuito, fuerza mayor, hecho de la víctima, hecho exclusivo de un tercero), así como normas de derecho público como, por ejemplo, el fundamento o respaldo constitucional de la cláusula general de responsabilidad patrimonial del Estado que se encuentra en el artículo 90 de la Constitución Política. La responsabilidad patrimonial del Estado, junto con la responsabilidad civil, forma parte del campo de estudio del derecho de daños.

Se encuentran muchos ejemplos que evidencian la aplicación mixta de normas de derecho privado y de derecho público. Por tal razón, algunos estudiosos consideran que el derecho debe ser estudiado como un derecho único que aplica de manera indiscriminada (por así decirlo) estas normas. Es fácil afirmar, entonces, que sí existe un derecho mixto. Pero surge otro interrogante: ¿qué denominación podríamos asignarle a este derecho mixto? Barón Barrera (2016) a este derecho mixto propone denominarlo como derecho económico, y lo define de la siguiente manera: "Como síntesis del derecho público y privado” (p. 41). 


\section{Noción del derecho económico}

Se debe reconocer que del derecho económico se han dado tantas nociones como autores se han ocupado del tema. Es inviable afirmar que el derecho económico y el derecho comercial se consideran sinónimos. Como si fueran la misma cosa. No. El derecho comercial, por excelencia, es un derecho privado. En cambio, el derecho económico, como se explicó, es un derecho mixto en relación con el derecho público y el privado.

En este texto se utilizará la noción del "derecho económico" como el derecho de la dirección e intervención del Estado en la economía. Por el carácter flexible que reviste la actividad intervencionista y de dirección por parte del Estado en los procesos económicos, el derecho económico es visto como un derecho dinámico. Algunos afirman que el derecho económico es el resultado de la transformación del derecho administrativo por dos de tantos factores: a) la ruptura de la ecuación derecho administrativo y administración pública; y b) la huida del derecho administrativo al derecho privado (Barón, 2016). Se debe advertir que el derecho administrativo no va a desaparecer. Está en crisis, pero su permanencia es justificable. Tal advertencia se debe a que el Estado, en sus actividades y procedimientos (o actuaciones administrativas), jamás deja de aplicar los principios de la función administrativa señalados en el Artículo 209 constitucional y porque, además, esta rama del derecho público está orientada a la efectiva garantía de los derechos de los asociados (Forero, 2020b).

Barón Barrera (2016), por ejemplo, sostiene que el derecho administrativo se transformó en derecho económico por la evidente ruptura de la ecuación derecho administrativo y administración pública a partir de "la injerencia creciente del derecho administrativo en órbitas reservadas al derecho privado" (p.27). Tal explicación tiene como antecedente lo reseñado por Juan Carlos Cassagne (2013) al precisar que:

El crecimiento progresivo del derecho administrativo contemporáneo sobre esferas de actuación reservadas con anterioridad en forma exclusiva al derecho privado y la necesidad de regular nuevas situaciones carentes de normación, han provocado la ruptura de la clásica ecuación que hacía generar el derecho administrativo únicamente alrededor del concepto de administración pública. ( p. 12)

De esta manera, la ruptura de la ecuación derecho administrativo y administración pública se refleja a partir de la evidente y creciente 
participación de personas jurídicas del derecho privado que cumplen funciones administrativas (o funciones públicas, para algunos), así como la prestación de servicios públicos domiciliarios. Lo anterior implica hablar de una transformación de la estructura del Estado en la medida en que la gestión pública, función pública y la función administrativa en gran parte están a cargo de los particulares. Es inviable afirmar que las personas jurídicas de derecho privado, al cumplir funciones administrativas, funciones públicas o prestan servicios públicos domiciliarios perderán su naturaleza de derecho privado. No. Estas siguen siendo de la órbita del derecho privado.

De la huida del derecho administrativo hacia al derecho privado, Barón Barrera (2016) ha explicado lo siguiente:

Nuestra posición es que la huida del derecho administrativo está asociada al modelo de desarrollo. En el neoliberalismo el derecho administrativo huye al derecho privado, pero sin abandonar el primero, sino que se aplica con mayor intensidad el segundo. En el intervencionismo de Estado se aplica con mayor intensidad el derecho administrativo sin abandonar el derecho privado. Tanto en neoliberalismo como en el intervencionismo de Estado se aplica el derecho público y privado, cuya sumatoria es el derecho económico. ( p. 33).

El autor alude a que el fenómeno de la huida del derecho administrativo se identifica con la aplicación rigurosa de normas de derecho privado en las actividades del Estado, pero sin abandonar la aplicación de las normas de derecho público en caso de intervención estatal, por ejemplo. Para el autor, tal mixtura equivale a derecho económico. Se debe advertir que la expresión huida del derecho administrativo hacia al derecho privado no significa que el derecho administrativo se desaparece del ordenamiento jurídico, sino que alude a la aplicación con mayor rigor de normas de derecho privado en las actividades del Estado, sin que ello implique que dejará de aplicar normas de derecho público. Lo advierte también Tafur Galvis (1996) quien señala que "se debe aclarar que, en ocasiones, esa huida, no conduce necesariamente hacia al derecho privado sino a la aplicación de regímenes especiales frente al ordenamiento general establecido, aunque dentro del ámbito del derecho público" (p. 103).

En todo caso, en las actividades del Estado se deben aplicar normas tanto de derecho público como de derecho privado. Tal combinación le permite a la doctrina hablar sobre la transformación de la estructura del Estado; tal como lo explica Marín Cortés (2008), la aplicación mixta de estas normas ha 
dado lugar para hablar de la existencia de transformación de la estructura del Estado moderno y se identifica con la alteración en la gestión de lo público, esto es, "de lo público en manos del Estado a lo público en manos privadas" (p. 192). Tal paradigma de transformación se debe a: i) gestión pública a cargo de los particulares, ii) las formas de gestión pública a cargo de los particulares y iii) la aplicación del derecho privado a la gestión de lo público (Marín, 2008).

Es pertinente, ahora, citar varias reflexiones referentes al fenómeno de huida del derecho administrativo hacia al derecho privado ofrecidas por la doctrina. Ariño Ortiz (2003) ha señalado dos consideraciones sobre este fenómeno. La primera indica que la huida del derecho administrativo se identifica con un "sorprendente proceso de privatización del Estado" (p. 93). La siguiente alude a que existen tres vías fundamentales en las que se ha manifestado este fenómeno respecto a la actuación del Estado: a) a través de la empresa pública; b) a través de la utilización de formas y régimen jurídico privado para la realización de actividades típicamente administrativas; y c) a través de privatización del propio derecho administrativo.

Tafur Galvis (1996), por su parte, ha señalado dos importantes explicaciones. La primera hace referencia a que "se ha asistido en los años a una aplicación de principios y reglas del derecho privado a las actividades y organización administrativas del Estado” (p. 95). La segunda, el autor explica que la aplicación creciente del derecho privado a las organizaciones estatales y las actividades a su cargo "se trata de fundar primordialmente en la necesidad de alcanzar agilidad, eficacia y eficiencia en la gestión y en la protección cabal a la libre iniciativa y a la libre competencia entre los agentes económicos, abstracción hecha de su origen” (p. 121).

Como se señaló en alguna oportunidad el derecho económico, según Barón Barrera (2016), es el derecho mixto en relación con el derecho público y privado. Pero en este texto se utilizará la explicación según la cual, el derecho económico es el derecho de la dirección e intervención del Estado en la economía. Así lo dan a entender Juan M. Farina (1999) y Ariño Ortiz (2003). El primer tratadista lo define de la siguiente manera:

Es el conjunto de normas que rigen la organización de la economía por los poderes públicos y regulan las actividades económicas de las personas privadas y del Estado, a fin de dar cumplimiento a la política económica puesta en práctica por el Estado. (Farina, 1999, p. 46) 
Ariño Ortiz (2003), por su parte, explica que el derecho económico se identifica con la reunión de "normas e instrumentos jurídicos a través de los cuales el Estado dirige la actividad económica" (p. 67). Nótese que ambos autores asocian las nociones de derecho económico con la institución de intervención del Estado en la economía. Se advierte, de nuevo, que del derecho económico se encuentra muchas nociones en la literatura jurídica y económica. La intervención del Estado en la economía, como se señaló en alguna oportunidad, tiene su fundamento constitucional que se encuentra en el Artículo 334 de la Constitución Política de Colombia y es vista como el desarrollo de la fórmula de Estado social de derecho (Constitución Política, 1991, Artículo 1), llamada a cumplir los fines estatales señalados en el Artículo 2 constitucional.

La intervención del Estado en la economía cuenta con varios tipos, tal como lo explica la Corte Constitucional en la Sentencia C-150 de 2003 como son: a) global (versa sobre la economía como un todo); b) sectorial (recae en una determinada área de actividad); c) particular (apunta a cierta situación); d) directa (recae sobre la existencia o la actividad de los agentes económicos); e) indirecta (está orientada no a la actividad económica sino al resultado de la misma); unilateral (cuando el Estado autoriza, prohíbe o reglamenta una actividad económica); convencional (cuando el Estado pacta con los agentes económicos); vía directiva (adopta medidas que orientan a los agentes económicos); vía de gestión (el Estado se hace cargo el mismo de actividades económicas por medio de personas jurídicas públicas). Con todos estos el Estado puede utilizar "respecto del funcionamiento de la económica y la organización de la sociedad" (Corte Constitucional de Colombia, Sentencia C-150, 2003, p.89). Sin dicha intervención, la economía no podría existir, menos funcionar.

\section{¿Cuál es la fuente del derecho económico?}

Como cualquier rama del derecho, el derecho económico halla sus fuentes en la Constitución Política, la Ley, los reglamentos, la jurisprudencia, y los principios generales del derecho. Barón Barrera (2016) considera que la fuente del derecho económico es el acto administrativo. El acto administrativo es definido como manifestación de voluntad unilateral (o acto jurídico unilateral) de quienes ejercen funciones administrativas encaminada a producir efectos jurídicos (Forero, 2020b).

En este texto se considera que es la Constitución Política su fuente principal. Se debe recordar sobre el fenómeno de la constitucionalización del derecho, 
que se caracteriza como un evento propio de los Estados contemporáneos (Corte Constitucional de Colombia, Sentencia C-034, 2009) el cual se ha convertido en exigencia que toda la normatividad vigente esté sometida en su interpretación y aplicación por la Constitución Política.

Por eso se afirma que todas las áreas del derecho se nutren por mandatos constitucionales (Corte Constitucional de Colombia, Sentencia T-006, 1992). Es la Constitución Política el documento que establece las directrices u orientaciones de funcionamiento de todo el sistema económico, político y social del país (Corte Constitucional de Colombia, Sentencia C-228, 2010). De esta manera, la Carta Magna debe observarse como la fuente principal del derecho económico, más la Constitución económica que está compuesta por los principios de la organización del Estado y el orden público económico.

Nuestra Constitución Política se identifica como una Constitución económica al señalar que toda persona tiene el derecho al trabajo (Artículo 25) y a una información y habilitación profesional y técnica (Artículo 54); la propiedad privada está garantizada (Artículo 58), más en la propiedad intelectual (Artículo 61) y en la propiedad de la tierra (Artículo 64); la calidad de los bienes y servicios ofrecidos en el país viene protegida en distintas maneras (Artículo 78) y el medio ambiente igualmente (Artículo 78); se debe promover la integración económica (Artículo 226); la libertad de empresa es la base del desarrollo con una función social que implica obligaciones (Artículo 333); la dirección general e intervención de la economía quedan encomendadas al Estado en caso de disfuncionalidades y dentro del marco de sostenibilidad fiscal (Artículo 334), las actividades financiera, bursátil, aseguradora, etc., se declaran de interés público (Artículo 335), se prohíben de manera general los monopolios, con excepción de los arbitrios rentísticos (Artículo 336), se le permite a la Ley establecer zonas de frontera especiales (Artículo 337) y se regulan los tributos (impuestos, tasas y contribuciones) (Artículo 338); el Plan Nacional de Desarrollo será elaborado dentro del marco de sostenibilidad fiscal (Artículo 339).

\section{Análisis económico del derecho. Una herramienta que propende por la eficiencia en las actividades económicas}

En el campo de estudio del derecho económico se estudia con frecuencia el análisis económico del derecho, AED. Esta es una herramienta que permite estudiar las normas o instituciones jurídicas con criterios económicos (Forero, 2019) o como lo explica Gutiérrez Prieto (2001), “es una aplicación de los 
métodos y teorías económicas a la regulación jurídica”. Esta herramienta se difunde ampliamente en los programas de derecho de las universidades, de ahí que "no existe campo alguno de la regulación jurídica que no haya sido mirado desde las perspectivas del análisis económico” (p. 5).

Con esta herramienta no pretende reemplazar la lógica jurídica, sino complementar. La anterior explicación es reseñada por Amador Cabra (2014) al señalar lo siguiente:

Desde la perspectiva teórica del AED es revolucionario debido a su aplicación de la metodología del razonamiento económico al derecho, no pretendiendo reemplazar la lógica jurídica, sino complementarla mediante el uso de la economía en relación con una gran cantidad de fenómenos legales. (Amador, 2014, p. 16)

Se coincide con quienes afirman que el derecho económico y AED no son sinónimos. No son la misma cosa. "Se tratan de dos formas de conocimiento que disponen de diferencias tanto en razón de sus objetos como en razón de sus metodologías” (Gutiérrez, 2001, p. 53). El AED es del campo de la ciencia económica. En cambio, el derecho económico es del derecho. Desde luego, un buen sector de la doctrina (diría doctrina mayoritaria) insiste que son sinónimos en la medida en que ambos estudian normas o instituciones jurídicas con métodos proporcionados por la ciencia económica.

Siguiendo a Amador Cabra (2014) el AED, al abordar el derecho desde una perspectiva económica, implica el desarrollo de estos tres elementos: a) la interpretación y examen de las normas se realizan desde una óptica económica; b) la racionalidad con que se dota a las leyes y al sistema normativo es la misma que utiliza la teoría microeconómica en su construcción teórica; y c) el entorno legal produce incentivos para que los agentes se comporten eficientemente.

Una de las instituciones más estudiadas en el AED corresponde a la eficiencia. Se advierte que no se debe confundir eficiencia con eficacia. La última alude al cumplimiento de metas, propósitos. En cambio, la eficiencia hace referencia en la optimización de recursos para el cumplimiento de metas. La eficiencia sí es estudiada con la economía, de ahí la denominación que ofrecen los economistas, eficiencia económica. Los agentes económicos (entre ellos se encuentra el Estado) deben, en sus actividades, propender por la eficiencia de las mismas. 
Amador Cabra (2014) entiende la eficiencia económica en dos sentidos: a) maximizar la producción y el beneficio; y b) distribuir lo producido entre los consumidores en función de sus preferencias. El autor aporta dos conclusiones frente a la eficiencia económica. La primera indica que la eficiencia, para el AED, desde el punto de vista normativo, es relevante, porque permite establecer cuáles son las condiciones para que los consumidores y productores optimicen el mercado. La segunda alude a que la eficiencia económica es un sistema de libre competencia donde oferentes y demandantes estudian sus alternativas, procurando sus beneficios. De esta manera, la eficiencia económica hace referencia al mejor uso alternativo que los agentes económicos (oferentes y demandantes) realicen de los bienes y servicios en el mercado.

\section{Noción del derecho administrativo}

En la literatura jurídica se encuentran muchas nociones del derecho administrativo. Younes Moreno (2016) entiende el derecho administrativo como "la rama del derecho público concerniente a la administración” (p. 3). Se debe advertir, a pesar de que el autor no señaló en la noción, que la administración alude a la administración pública. Montaña Plata (2010), por su parte, define el derecho administrativo como el derecho de la función administrativa.

Tanto la administración pública como la función administrativa aluden a toda actividad desplegada por parte del Estado para el cumplimiento de los fines estatales, siempre al servicio del interés general. Ambas son instrumentales, puesto que sirven a la consecución de los fines del Estado. El Artículo 209 de la Constitución Política asocia a la institución de función administrativa al señalar que "la función administrativa está al servicio de los intereses generales y se desarrolla con fundamento en los principios de igualdad, moralidad, eficacia, economía, celeridad, imparcialidad y publicidad".

Es de considerar que algunos estudiosos dan a entender que la administración pública es una noción que posee dos sentidos, eso sí, no excluyentes sino complementarios. Vidal Perdomo (1966), por ejemplo, define la administración pública como "el conjunto de órganos encargados de cumplir las múltiples intervenciones del Estado moderno y prestar los servicios que el Estado atiende” (p. 2). El autor señala, entonces, que la administración pública alude a los órganos (sentido orgánico), así como a la prestación de servicios (sentido material o funcional). Esta última faceta se caracteriza como forma 0 manifestación de intervención del Estado en la economía. 
En relación con la intervención del Estado en la economía, es temática propia del derecho económico, y no de derecho administrativo. Así lo da a entender Vidal Perdomo (2004): "Una nueva rama del derecho está en formación: el derecho económico. La teoría de la intervención del Estado en la economía, los campos de regulación de la actividad económica de los particulares (...), hacen parte de esta disciplina” (p.4). De esta manera, permite concluir que hasta los administrativistas poco a poco reconocen que el estudio de la intervención del Estado en la economía es de derecho económico.

\section{¿Cuál es la fuente del derecho administrativo?}

Como cualquier rama del derecho, las fuentes del derecho administrativo son la Constitución Política, la Ley, los reglamentos, la jurisprudencia y los principios generales del derecho. Algunos consideran que la fuente principal del derecho administrativo es la jurisprudencia (conjunto de sentencias proferidas por los jueces y magistrados) en virtud de la aplicación de los artículos 10, 102 y 267 de la Ley 1437 de 2011, Código de Procedimiento Administrativo y de lo Contencioso Administrativo.

La primera disposición, Artículo 10, alude a que "al adoptar las decisiones de su competencia, [las autoridades] deberán tener en cuenta las sentencias de unificación jurisprudencial del Consejo de Estado (...)”. El Artículo 102 hace referencia a que las autoridades "deberán extender los efectos de una sentencia de unificación dictada por el Consejo de Estado, en la que se haya reconocido un derecho, a quienes lo soliciten y acrediten los mismo supuestos fácticos y jurídicos". La siguiente disposición, el Artículo 267, indica que "si se niega la extensión de los efectos de una sentencia de unificación o la autoridad hubiere guardado silencio" frente a la solicitud de extensión de jurisprudencia, “(...) el interesado podrá acudir ante el Consejo de Estado mediante escrito razonado, al que acompañará la copia de la actuación surtida ante la autoridad competente".

En este texto se insiste en que la fuente principal del derecho administrativo es la Constitución Política, que está compuesta por los principios de la organización del Estado y el orden público. Es de resaltar que todas las áreas del derecho están nutridas por mandatos constitucionales. Younes Moreno (2016) entiende por Constitución Política como "el conjunto de reglas que definen y regulan la integración y funcionamiento de los órganos del Estado y señala los derechos, garantías y obligaciones fundamentales de los integrantes de la comunidad política” (p.4). 


\section{El régimen jurídico de las empresas industriales o comerciales del Estado. Aspectos generales}

Corresponde señalar, primero, sobre la adecuada utilización de denominaciones. Rodríguez Rodríguez (2012) utiliza la denominación empresas industriales y comerciales del Estado, y así lo ha señalado la Ley 489 de 1998, "por la cual se dictan normas sobre la organización y funcionamiento de las entidades del orden nacional”. Marín Vélez (2016), por su parte, emplea como empresas industriales o comerciales del Estado y así lo reseña el Artículo 115 de la Constitución Política de Colombia. Es de considerar que no todas las empresas cumplen con las dos funciones: industrial y comercial. Algunas pueden cumplir función solamente industrial. Otras exclusivamente comercial. Y otras cumplen con las dos.

El fundamento constitucional de dichas empresas se encuentra en el Artículo 115 de la Constitución Política, al advertir que "las (...) empresas industriales o comerciales del Estado forman parte de la Rama Ejecutiva”. Se inscriben dentro de la clasificación de la descentralización por servicios y, por lo tanto, están sujetas a un control de tutela por el poder central, control político por el Congreso de la República y un control jurisdiccional sobre la legalidad de sus actos y contratos. De ahí que el régimen de las empresas industriales o comerciales del Estado se encuentre constitucionalizado. El gerente o presidente de las mismas son designados por el presidente de la República a través de acto administrativo de libre nombramiento y remoción (Artículo 89, Ley 489, 1998).

Según el Artículo 85 de la citada Ley 489, estos son organismos creados por la Ley o autorizados por esta, que adelantan actividades de naturaleza industrial o comercial y de gestión económica conforme a las reglas del derecho privado. Las características de dichas empresas son: a) personería jurídica; b) autonomía administrativa; y c) capital independiente (constituido totalmente con bienes o fondos públicos comunes, los productos de ellos, o el rendimiento de tasas que perciban por sus funciones o servicios, y contribuciones de destinación especial en los casos autorizados). El capital de estas empresas podrá representarse en cuotas o acciones de igual valor nominal. No se deben confundir las sociedades de economía mixta que, de acuerdo con el Artículo 461 del Código de Comercio (Decreto 410 de 1971), son aquellas que "se constituyen con aportes estatales y de capital privado”. 
Las empresas industriales o comerciales del Estado como personas jurídicas surgen de la Ley (Congreso de la República), ordenanza (Asamblea departamental) o acuerdo (Concejo municipal). Distinto sucede con las sociedades de economía mixta, estas surgen del contrato de sociedad comercial. No confundir contrato comercial con contrato de sociedad comercial. Este último, según el Artículo 98 del Código de Comercio, se da cuando “dos o más personas se obligan a hacer un aporte en dinero, en trabajo o en otros bienes apreciables en dinero, con el fin de repartirse entre sí las utilidades obtenidas en la empresa o actividad social”.

Estas empresas son estudiadas como organismos vinculados y ese carácter de vinculados alude a la autonomía que tienen con la administración central. Su autonomía es mayor. Así lo explica Rodríguez Rodríguez (2012) “en el sentido de que gozan de mayor autonomía respecto de esta, comparativamente con la situación de las entidades adscritas (p. 119). Desde luego, Marín Vélez (2016) considera que tal autonomía no debe entenderse en términos absolutos sino relativos, por cuanto hay normas expedidas por el Presidente de la República, que determinan la estructura y funcionamiento de dichas empresas, como ocurre con el Decreto 2163 de 2008 aplicable para SATENA (Servicio Aéreo a Territorios Nacionales).

Respecto de la autonomía administrativa y financiera, de acuerdo con el Artículo 86, esta se ejercerá conforme a los actos que las rigen. En el cumplimiento de sus actividades se ceñirá a la norma que las creó o autorizó y a sus estatutos internos. La doctrina insiste, y así lo señala la norma en cita, que no podrán destinar cualquier parte de sus bienes o recursos para fines diferentes de los contemplados en la Ley o en sus estatutos internos. Además de las actividades o actos previstos en la Ley o estatutos, podrán desarrollar y ejecutar todos aquellos que sean necesarios para el cumplimiento del objeto asignado.

Se debe señalar que, al realizar actividades de naturaleza económica (comercial, industrial y de gestión económica), dichas empresas ejercen con ánimo de lucro. Se comparten las reflexiones ofrecidas por Rodríguez Rodríguez (2012) al señalar que "este ánimo de lucro no es igual al que mueve a los particulares” (p.121). Tal reflexión se debe a que las utilidades de dichas empresas son para el cumplimiento adecuado de los fines estatales. Mientras que las utilidades de los particulares son para ellos mismos, "con fines egoístas y personales” (Rodríguez, 2012, p. 121). Tal explicación la menciona también Tafur Galvis (1996), quien señala lo siguiente: 
En la medida en que el Estado asume actividades de gestión económica, libradas en el pasado a la iniciativa privada, encuentra que las formas jurídicas tradicionales no son adecuadas; debe crear nuevos mecanismos o adaptar los ya existentes. En ese orden de ideas aparece que mientras las personas públicas están diseñadas para la prestación de servicios públicos o el ejercicio de funciones administrativas privativas del Estado, las empresas creadas por los particulares han surgido con la finalidad específica de ejercer gestión económica, a través de la industria y comercio. Por ello la tendencia inicial será la de asimilar las entidades creadas por el Estado para la gestión directa de actividades industriales y comerciales, a las empresas de los particulares. Orientación esta que se ve impulsada por los supuestos alicientes, de esquivar la aplicación del régimen de derecho público, y de evitar los controles administrativos y financieros que gravitan sobre las personas públicas. Empero la orientación descrita no consulta la integridad del fenómeno intervencionista, toda vez que para el Estado la obtención de una ganancia económica, como resultado de la gestión de la empresa, es solo medio para el logro de los fines sociales. Por el contrario, para el empresario particular, la obtención de la utilidad económica es la finalidad esencial de su empresa. (Tafur, 1996, p. 177)

Las empresas industriales o comerciales del Estado gozan de privilegios y prerrogativas que la Constitución Política y las leyes les confieren (y a las entidades territoriales), según sea el caso. Salvo que estas, que por "razón de su objeto compitan con empresas privadas”, no podrán ejercer aquellas prerrogativas y privilegios que impliquen menoscabo de los principios de igualdad y de libre competencia frente a las empresas de derecho privado.

Se señaló en alguna oportunidad que el gerente o presidente de estas empresas, que son los representantes legales de las mismas (Artículo 89), se designan por el Presidente de la República. Según el Artículo 88, la dirección y administración de las mismas estará a cargo de una junta directiva y de un gerente o presidente. De ahí que la calidad y los deberes, régimen de inhabilidades e incompatibilidades, así como de la remuneración de los miembros de la junta se regirán por las disposiciones aplicables a los establecimientos públicos conforme a la Ley 489 de 1998, así lo advierte el Artículo 89.

Se ha preguntado con frecuencia si son o no comerciantes. Linares Vesga (2001) asegura que son comerciantes y los denominan como "comerciantes de derecho público” (p. 69). Pero no explicó si se debe aplicar el criterio objetivo o subjetivo para determinar la calidad de comerciante. En este texto se considera 
que al aceptar la tesis según la cual son comerciantes las empresas industriales o comerciales del Estado, a estas empresas se les deben aplicar el criterio objetivo (que profesionalmente ejecuta actos que la ley considera mercantiles) y no el criterio subjetivo (que se inscribe como tal en el registro mercantil).

Madriñán de la Torre (2004) también considera que estas empresas son comerciantes y se identifican como ejemplo del denominado Estado comerciante o Estado empresario:

El Estado comerciante. Como se anotó en el capítulo correspondiente a la evolución histórica del derecho comercial, desde el momento en que el Estado abandonó su posición de gendarme y comenzó a intervenir y a dirigir la economía en interés de terceros y de la comunidad en general, se planteó claramente la posibilidad de su participación en el ejercicio del comercio. Y es así como, asumiendo directamente los riesgos o compartiéndolos con particulares, el Estado viene actuando en el mundo jurídico-mercantil con las características de un comerciante, aunque, como es obvio, está previsto al respecto un régimen estrictamente público.

En Colombia esa actuación del Estado corresponde a las formas de las empresas industriales y comerciales del Estado y de las sociedades de economía mixta, definidas en los artículos 85 y 87 de la Ley 489 de 1998 , calificadas en ella como entidades de la administración y, por lo tanto, como verdaderos sujetos de derecho público.

Nuestro ordenamiento jurídico, en relación con las empresas industriales y comerciales del Estado, prevé su autonomía administrativa y financiera (Artículo 86 de la Ley 489 de 1998), condición que es esencial para poderlos calificar como empresarios públicos y, por lo tanto, como verdaderos sujetos de la actividad mercantil. (Madriñán, 2004, pp. 98-99)

Tafur Galvis (1974), por su parte, ha negado el calificativo de comerciantes a dichas empresas al advertir lo siguiente:

En el derecho colombiano, las llamadas empresas industriales y comerciales del Estado están excluidas subjetivamente de las regulaciones del Código de Comercio; no están sometidas a las obligaciones que son propias de los comerciantes, aunque por aplicación del Art. 11 del propio Código de Comercio, estarán sujetas a las normas comerciales en cuanto realicen operaciones que tengan la condición de actos de comercio. (Tafur, 1974, pp. 150-151) 
Resulta pertinente señalar que hay normatividades que permiten concluir que estas empresas sí realizan actos de comercio y, por tanto, son considerados como comerciantes. Así lo da entender el Artículo 13 de la Ley 80 de 1993, Estatuto General de Contratación de la Administración Pública, al precisar que "los contratos que celebren las entidades (...) se regirán por las disposiciones comerciales y civiles pertinentes”. Y lo resalta igualmente el Artículo 93 de la Ley 489 citada al advertir que los actos y contratos que expidan estas empresas para el desarrollo de su actividad propia (industrial, comercial o de gestión económica) "se sujetarán a las disposiciones del derecho privado”. На de advertir que a estas no se les aplica el código subjetivo de los comerciantes.

Y, finalmente, Castro de Cifuentes (2016) considera que dichas empresas deben ser vistas como empresarios: "No obstante, consideramos conforme a lo expuesto, que dichas entidades son empresarios desde la preceptiva constitucional, que otorga a la empresa y al empresario una connotación más amplia e incluyente que aquella reconocida por el derecho mercantil” (Castro, 2016, p. 420).

En relación con los trabajadores oficiales, dada su vinculación laboral contractual, son objeto de aplicación, en parte, del Código Sustantivo de Trabajo (Rodríguez, 2012). Todos los empleados y trabajadores son trabajadores oficiales. Lo anterior es la regla general cuya excepción es la siguiente: los que ocupan cargos de dirección y confianza en los cuales posean la calidad de empleados públicos, que no son vinculados mediante contrato de trabajo, sino que son a través de acto administrativo de libre nombramiento. Los empleados públicos son de libre nombramiento y remoción (Marín, 2016).

Se ha presentado una discusión en relación con el régimen jurídico aplicable a los servidores públicos de las empresas industriales y comerciales del Estado que prestan servicios públicos. A este respecto la Corte Constitucional, en la Sentencia C-253 de 1996 señaló lo siguiente:

Estima la Corte que el Artículo 41 de la Ley 142 de 1994, al disponer que el régimen de los servidores de las empresas de servicios públicos domiciliarios que adopten la forma de empresas industriales y comerciales del Estado, es el consagrado en el inciso primero del Artículo 5 del Decreto 3135 de 1968 relativo a los empleados públicos, y no al inciso 2. ․ de la misma disposición que se refiere a los trabajadores oficiales, resulta contrario a la Carta Política en el aparte acusado, por las siguientes razones: 
Con la remisión aludida se desconoce el principio constitucional de la igualdad de quienes prestan sus servicios a las empresas industriales y comerciales del Estado, por cuanto estas, por regla general, vinculan a las personas que laboran para ellas en calidad de trabajadores oficiales, como lo señala el actor, y de manera excepcional de conformidad con sus estatutos, a quienes desempeñen cargos de dirección y confianza se les otorga la categoría de empleados públicos, de acuerdo con lo dispuesto en el Artículo 5 del Decreto 3135 de 1968. (Corte Constitucional de Colombia, Sentencia C-253, 1996, pp. 15-16)

Se finaliza con la advertencia, según la cual se deben aplicar normas de derecho público a los actos administrativos expedidos por dichas empresas y son sujetos a controles administrativos (recursos de vía administrativa), así como a controles judiciales (medio de control de nulidad y restablecimiento del derecho, por ejemplo). La expedición de actos administrativos se da por el ejercicio de la función administrativa, por eso se dice que el acto administrativo es el resultado del ejercicio de la función administrativa (Forero, 2020b). Entendemos por acto administrativo aquel acto jurídico unilateral de quienes ejercen funciones administrativas encaminado a producir efectos jurídicos.

\section{¿Es de derecho administrativo el régimen jurídico de las empresas industriales o comerciales del Estado?}

Como se explicó en varias ocasiones, por ser parte de la rama ejecutiva del poder público o porque su creación se da por virtud de la voluntad del Estado, el régimen jurídico de las empresas industriales o comerciales del Estado es de derecho administrativo. En este texto se propende por la conveniencia de hablar de derecho económico cuando nos referimos al régimen jurídico de dichas empresas, entendiendo por derecho económico como el derecho de la dirección e intervención del Estado en la economía. Para fortalecer nuestra propuesta es pertinente citar varias reflexiones de varios autores que asocian a tales empresas como instrumento de intervención del Estado en la economía.

Castro de Cifuentes (2016) señala que "dichas empresas forman parte de la estructura de la administración pública colombiana y son manifestaciones de la intervención del Estado en la economía” (p. 417). En párrafos siguientes concluye que "si bien se crean para desarrollar actividades comerciales e industriales, se hacen para cumplir finalidades públicas, satisfacer necesidades de la comunidad, fomentar sectores productivos estratégicos para el desarrollo económico y, en fin, lograr finalidades de interés general” (p. 417). Ya que la 
autora asocia en la conclusión al desarrollo económico, esta también es una institución que forma parte del campo de estudio del derecho económico. De ahí que cuando las empresas industriales o comerciales del Estado contribuyen el desarrollo económico a través de la ejecución de sus actividades eso es derecho económico.

Marín Vélez (2016), de manera tímida, da a entender que la creación de estas empresas es una forma de intervención económica del Estado al señalar lo siguiente: "obedece a la necesidad de mantener control sobre inversión de recursos que provienen del erario público en tales actividades; o por la necesidad de fijar políticas de precios, o para regularlos, entre otras posibilidades de intervención económica” (p.152).

Tafur Galvis (1996) ha afirmado que la creación de estas empresas por parte del Estado es una de las modalidades de intervención del Estado en la economía. Esta explicación ha sido difundida desde el año 1978:

En efecto, cabe recordar que el Artículo 32 de la Carta Política de Colombia, al consagrar el reconocimiento y garantía de la libertad de empresa y de la iniciativa privada, plantea el predominio, en nuestro sistema económico y jurídico, del principio de la subsidiariedad para la actividad empresarial del Estado. Empero, dicho principio ha de entenderse en armonía con aquel otro que proclama la dirección general de la economía de parte del Estado y la necesidad de que este intervenga en la vida económica. Naturalmente, que la intervención reviste variadas modalidades y mecanismos, uno de los cuales consistirá en la creación de empresas por parte del Estado y cuya dirección y gestión estará a su cargo, de manera exclusiva o por lo menos predominante. (Tafur, 1996, p. 177)

Ayala Caldas (1994) aporta tres importantes consideraciones muy relacionadas con la teoría de intervención del Estado en la economía ante la creación de empresas industriales o comerciales del Estado. La primera indica que estas empresas "son una forma típica de intervencionismo estatal y se justifican por la necesidad de intervenir económicamente el Estado” (p.88). La siguiente alude a que su creación se da "por motivos de interés público y social para garantizar la prestación de servicios eficientes y a bajo costo" (p. 88). Y como tercer, y última conclusión, estas empresas "realizan una actividad empresarial, económica, pero en busca de satisfacer intereses de la comunidad” (p. 88). 
En sentido coincidente explica Gómez Aranguren (2004), quien señala lo siguiente:

Responden a los lineamientos propios del Estado interventor, es decir a la secuencia que muestra la transformación del Estado abstencionista de la clásica versión del estado liberal en uno que impacta la actividad de los particulares no solo imponiendo reglamentos y prescripciones sino que su participación ocurre mediante su ingreso en el proceso económico mismo, como alternativa para ejecutar actividades de fomento, de incentivar a un determinado frente de la economía o para suplir un área en la que pese a corresponderle a la iniciativa privada, ésta no responde y ante tal vacío, el proceso económico en general acusa un tipo de resentimiento. Las empresas del Estado en esta medida muestran una posición polifuncional, pues a la par tienen efecto allí donde éste participa en actividades colectivas por fuera de márgenes del servicio público, también impulsa el desarrollo económico en frentes que se juzga, lo requiere para beneficio colectivo (Gómez, 2004, p. 163).

Herrera Robles (2001), por su parte, al explicar las justificaciones de creación de estas empresas también asocia a la intervención del Estado en la economía al señalar lo siguiente:

Son varias las razones que justifican la creación de una empresa industrial y comercial del Estado, en sus distintos órdenes. De manera general, podemos distinguir tres situaciones: a) cuando se trata de actividades que afectan la seguridad nacional, como en el caso de fabricación de armas; b) cuando se trata de actividades que afectan la estabilidad económica o social o que tienen incidencia determinante en los procesos productivos, como la explotación de hidrocarburos; c) cuando se trata de actividades que no obstante ser necesarias, los particulares no muestran interés en asumirlas, ya sea porque no son rentables o porque involucran un volumen de capital del que no disponen, o porque la actividad genera un nivel tan alto riesgo que no se compara con la utilidad. De manera específica, la creación de estas empresas puede estar motivada en la administración de un monopolio o en una dinámica de intervención en la economía, buscando los fines de interés social a que se refiere el Artículo 334 constitucional. (Herrera, 2001, p. 102)

Madriñán de la Torre (2004) ha concluido que algunas formas de dirigismo del Estado en la economía se manifiestan con la presencia de empresas industriales y comerciales del Estado: 
En efecto, los esquemas clásicos del derecho mercantil fueron afectados en dos sentidos que se resumen en lo que algunos autores han llamado el fenómeno de publificación del derecho privado y que se concretan, el primero, en la formulación de normas mediante las cuales el principio de la libertad contractual es limitado en busca de adecuada protección de los terceros (trabajadores, ahorradores, etc.) y, el segundo, en la posición que el Estado ha asumido en la dirección de la economía, la cual supone la adopción de claros criterios de derecho público en los que el principio de que los sujetos no tienen facultades distintas de la que la ley expresamente les concede, sustituye al de la autonomía de la voluntad.

Algunas formas de dirigismo se manifiestan con la presencia de empresas industriales y comerciales del Estado y los estatutos excepcionales formulados para ciertos comerciantes. En las primeras, como su nombre lo indica, el Estado asume la ejecución directa de actividades mercantiles (servicios, industrias, etc.); en los segundos, orienta y precisa la actividad de personas particulares. (Madriñán, 2004, pp. 19-20)

Y finalmente, Hernández Quintero (2018) también ha señalado que la dirección e intervención económica por parte del Estado puede efectuarse, entre otras, con la creación de empresas industriales o comerciales y resalta que tal intervención tiene su origen principal en la Constitución Política de 1886. Es pertinente citar la conclusión del autor: "La intervención del Estado en la economía puede efectuarse de múltiples formas como ha sucedido en Colombia. Bien puede tratarse de (...) la creación de empresas puramente estatales que compiten con los particulares (...)” (p. 58).

De esta manera, es forzoso concluir que el régimen jurídico de las empresas industriales o comerciales del Estado es de derecho económico y no de derecho administrativo. Entendiendo por derecho económico como el derecho de la dirección e intervención del Estado en la economía y la creación de dichas empresas es una modalidad de intervención económica por parte del Estado.

Barón Barrera (2016) está de acuerdo con la consideración de derecho económico, según la cual el derecho es aplicable a estas empresas, pero con una noción diferente frente al derecho económico, que es definido como el derecho mixto en relación con el derecho público y con el derecho privado:

El régimen jurídico de la empresa del Estado es el derecho económico, porque se le aplica tanto el derecho público (creación legal, gerente nombrado por 
el presidente, contratación estatal, controles estatales) como el derecho privado (Código Civil, Comercial y Laboral) en las actividades económicas relacionadas con su objeto industrial y comercial. (Barón, 2016, p. 96)

Tal mixtura también es explicada por Tafur Galvis (2016) al precisar lo siguiente: "Los factores característicos de las empresas públicas se proyectan en los distintos rasgos del régimen jurídico a ellas aplicable, haciendo surgir un régimen intermedio, inspirado en principios originarios del derecho público, de una parte, y del derecho privado, de otra (Tafur, 1996, p. 180). En sentido coincidente, explica Madriñán de la Torre (2004) lo que se enuncia a continuación: al señalar que estas “están sometidas a un régimen de derecho público, pero sus actos o contratos, por lo general, salvo las excepciones establecidas en la ley, corresponden a la disciplina de la ley civil y comercial” (p.99).

De esta forma, tales empresas se sujetan a normas jurídicas en cuya formación concurren principios de derecho privado con principios de derecho público, generando un régimen jurídico mixto y eso equivale a derecho económico. Entendiendo por este último, siguiendo a Barón Barrera (2016), como el derecho mixto en relación con el derecho público y el privado.

En la academia se ha sostenido que, al identificar como actividades de derecho comercial las de perfil industrial, comercial y de gestión económica o empresarial, tales empresas deben ser de derecho comercial. Sostenemos que no es una explicación adecuada por cuanto el derecho comercial es por excelencia derecho privado, y las empresas industriales y comerciales del Estado su régimen jurídico es mixto (derecho público y derecho privado). De esta manera, no es conveniente hablar de derecho comercial cuando hacemos referencia al régimen jurídico de las empresas industriales o comerciales del Estado. Además, las actividades comerciales, industriales y de gestión económica también se identifican con el derecho económico y no resulta desacertado considerar que el régimen jurídico de las empresas en comento es de derecho económico. Por ello, se comparte la reflexión ofrecida por Tafur Galvis (1996) al advertir lo siguiente:

Si bien es cierto que las empresas públicas estatales, normalmente actúan en la gestión económica, industrial o comercial, procedimientos en el régimen de derecho privado, es evidente que su participación en el mercado económico persigue finales de interés general, social y constituyen instrumentos efectivos de la intervención estatal en el ámbito económico. (Tafur, 1996, p. 188) 
La anterior se identifica en términos como mercado económico, interés general e intervención en el ámbito económico; estos también forman parte del campo de estudio del derecho económico.

En este texto coincide con las explicaciones ofrecidas por la doctrina, al señalar que es inviable afirmar que la actividad comercial, industrial y de gestión económica se debe identificar en términos absolutos como ejercicio de la función administrativa. Se comparte, porque las actividades económicas aluden a la producción, transformación, circulación, administración y custodia de bienes y no como ejercicio de función administrativa. Lo anterior, tal como lo expone Peña Nossa (2014), "implica la existencia de una cadena de intermediación que inicia desde el productor hasta el producto final" (p.12). Tales actividades son del mundo del derecho económico. La función administrativa es del derecho administrativo.

No hay discusión que en la rama ejecutiva del poder público se estudia la administración pública, así como la función administrativa, y estas se identifican bastante con "la ejecución de las leyes, aplicación técnica e implementación de las políticas demarcadas por las políticas del gobierno" (Corte Constitucional de Colombia, Sentencia C-910, 2007, p. 31). Pero resulta acertada la crítica que ofrece Marín Vélez (2016) al precisar que "la actividad de las empresas que son industriales y comerciales, o comerciales o industriales difieren notoriamente de la función de la rama ejecutiva, cual es ejecutar la ley” (p.151). En página siguiente, el autor expone este ejemplo:

Si se cita un ejemplo, por poner un caso, el relativo a la comercialización de la sal, la empresa organizada con tal fin podría obedecer a una intervención en materia económica o para regular su precio, o para evitar que sea objeto de monopolio o que se abuse de sus precios, por ser producto de primera necesidad para la alimentación, pero difícilmente se entendería que tiene que ver esa actividad con la ejecución de la Ley. (Marín, 2016, p. 152)

Marín Vélez (2016) ha sido enfático en señalar que no comparte con quienes afirman que la ejecución de la Ley puede corresponder igualmente a la actividad administrativa del Estado, "sigue siendo difícil encuadrar esa clase de actividad dentro de las de administrar, dados los fines que persiguen, y por ello, no cabría encajarlas ni en la rama ejecutiva ni en la administración nacional” (p.152). 
En sentido coincidente critica Brito Ruíz (2013), quien señala lo siguiente:

En cuanto a las empresas industriales o comerciales del Estado, procede señalar, inicialmente, que aparecen incluidas en el Artículo 115 de la Carta, que trata de la rama ejecutiva. Esto genera alguna dificultad de comprensión, en tanto se considere que esta rama cumple las denominadas funciones ejecutivas, porque ellas, de existir, corresponderían a unas distintas de las que realizan esas industrias o empresas, encaminadas al sector productivo de la economía, antes que a labores relacionadas con la ejecución de la Ley. En otro sentido, resulta difícil entender de qué manera se cumple la ejecución de la ley mediante una actividad industrial o comercial. (Brito, 2013, pp. 434-435)

Por eso Vidal Perdomo (2004) ha concluido que dichas empresas no deben ser estudiadas dentro de la rama ejecutiva por cuanto no ejercen funciones administrativas:

Sin embargo, desde la ley aparece una noción de función administrativa más amplia, ligada a la noción de administración pública, que puede comprender a los órganos de control como las contralorías y la Procuraduría General de la Nación, que no ingresan fácilmente dentro del concepto de rama ejecutiva; pasa otro tanto con las administraciones departamentales y municipales que por virtud del principio de la descentralización no entran bien dentro del concepto de rama ejecutiva que se refiere a organismos nacionales; la misma consideración juega respecto a empresas industriales y comerciales y sociedades de economía mixta, que no es propio ponerlas dentro de la rama ejecutiva puesto que no ejercen funciones de poder 0 autoridad de Estado. (Vidal, 2004, p. 79).

Se insiste en este texto que no es viable identificar la actividad comercial, industrial y de gestión económica con la actividad de ejecución de la Ley o con la función administrativa. Tales actividades económicas son del mundo del derecho económico. La actividad de ejecución de la Ley y el cumplimiento de la función administrativa, son del mundo del derecho administrativo. La actividad de ejecución de la Ley es distinta que la actividad económica. Claro está que, tal como lo advierten Rodríguez Rodríguez (2012) y Ayala Caldas (1994), de manera excepcional, la Ley puede conferir a las empresas mencionadas funciones administrativas. 
Antes de analizar la aplicación del AED en el régimen jurídico de dichas empresas, se considera importante señalar que el régimen jurídico de las empresas industriales o comerciales del Estado tienen incidencia social y económica. Social, porque dichas empresas están siempre al servicio del interés general. Económica, porque hace circular o distribuir la riqueza. Las empresas industriales o comerciales del Estado, por su incidencia social y económica, son una herramienta de desarrollo. La característica social proviene tanto del derecho administrativo como del derecho económico, y la característica económica es propia del derecho económico. Lo anterior permite afirmar que el régimen jurídico de las empresas industriales o comerciales del Estado es derecho económico.

\section{¿Es aplicable el AED en el régimen jurídico de las empresas industriales o comerciales del Estado?}

Al aplicar el derecho económico, el régimen jurídico de las empresas industriales o comerciales del Estado resulta aplicable también el AED y decíamos que este alude al examen de normas o instituciones jurídicas con criterios económicos. Se explicó, igualmente, que en el campo de estudio del AED se analiza la eficiencia que hace referencia a la optimización de recursos para el cumplimiento de meta o propósito.

La eficiencia no es propia del campo de estudio del derecho administrativo, específicamente al hablar del cumplimiento de la función administrativa en virtud del Artículo 3 de la Ley 1437 de 2011. También es estudiada en el derecho económico, más en el AED. Es aplicable en la función administrativa, así como en las actividades económicas. La eficiencia es estudiada como sinónimo con la economía, es tanto que los economistas han propuesto utilizar la denominación "eficiencia económica”. Con el AED se propende por la eficiencia en las actividades económicas, también lo es en la función administrativa.

La eficiencia económica se relaciona con la elección de los medios o recursos más adecuados para el cumplimiento de los objetivos. Con ella permite la verificación objetiva de la identificación, producción y distribución de bienes y servicios de las empresas industriales o comerciales del Estado destinados a la consecución de los fines estatales propuestos por el Estado social de derecho. El logro de estos fines requiere de actividades económicas o de una función administrativa eficiente que responda a las exigencias del Estado social de derecho. 
De ahí que la fórmula de Estado social de derecho es desarrollada, entre otras (o principalmente, para algunos), por la dirección e intervención del Estado en la economía, y dentro de él se encuentra como modalidad o como instrumento la creación de las empresas industriales o comerciales del Estado. Y para cumplir los fines estatales dichas empresas requieren de recursos suficientes, infraestructura adecuada, personal calificado, entre otros.

De esta manera, la eficiencia económica hace referencia al mejor uso alternativo que las empresas industriales o comerciales del Estado realicen tanto de sus actividades económicas como de las funciones administrativas.

\section{Conclusiones}

- El derecho económico es definido como el derecho de la dirección e intervención del Estado en la economía. Dentro del campo de estudio de esta rama del derecho se aplica el análisis económico del derecho, AED, consistente en un examen de normas o instituciones jurídicas con criterios económicos, y en él se estudia con frecuencia con la eficiencia, que alude a la optimización de los recursos para el cumplimiento de metas. Por derecho administrativo se entiende como aquel de la administración pública.

- Las empresas industriales o comerciales del Estado son organismos creados por la Ley o autorizados por esta, que desarrollan actividades de naturaleza industrial o comercial y de gestión pública conforme a las reglas del derecho privado y poseen personería jurídica, autonomía administrativa y financiera, y capital independiente. Estas son vistas por la doctrina como instrumentos de dirección e intervención del Estado en la economía.

- Se concluye que el régimen jurídico de dichas empresas, por ser estas como modalidades o instrumentos de intervención del Estado en la economía, es de derecho económico y no de derecho administrativo. Como se señaló, el derecho económico es entendido como el derecho de la dirección e intervención del Estado en la economía.

- El régimen jurídico de las empresas industriales o comerciales del Estado tienen incidencia social y económica. Social, porque dichas empresas están siempre al servicio del interés general. Económica, porque hace circular o distribuir la riqueza. Las empresas industriales o comerciales del Estado, por su incidencia social y económica, es una herramienta de desarrollo. La característica social pertenece tanto del derecho administrativo como del derecho económico, y la característica económica es propia del derecho 
económico. Lo anterior permite afirmar que el régimen jurídico de las empresas industriales o comerciales del Estado es derecho económico.

- Al ser parte del derecho económico resulta entonces aplicable el AED, que propende por la eficiencia en las actividades económicas. Tal explicación contribuye a un mejor estudio, a un análisis de manera coherente.

\section{Referencias}

Amador Cabra, L. E. (2014). Análisis económico del derecho: un paradigma en construcción. En Serie de Derecho Económico No. 3. (13-50). Ediciones Universidad Externado de Colombia

Ariño Ortiz, G. (2003). Principios de derecho público económico. Ediciones Universidad Externado de Colombia.

Ayala Caldas, J. E. (1994). Elementos de derecho administrativo colombiano. Ediciones Doctrina y Ley Ltda.

Brito Ruíz, F. (2016). Estructura del Estado colombiano y de la administración pública nacional. Ediciones Legis.

Bobbio N. (1994). Teoría general del derecho. Ediciones TEMIS.

Cassagne, J. C. (2013). La teoría del acto administrativo. Ediciones TEMIS.

Castro de Cifuentes, M. (2016). Derecho comercial: actos de comercio, empresas, comerciantes y empresarios. Ediciones TEMIS - Universidad de Los Andes.

Farina, J. M. (1999). Contratos comerciales modernos. Ediciones ASTREA.

Forero Hernández, C. F. (2019). El derecho tributario, ¿derecho administrativo o derecho económico? En Dos Mil Tres Mil No. 21. https://doi.org/10.35707/dostresmil/2101

Forero Hernández, C. F. (2020a). El contrato estatal. Ediciones Unibagué

Forero Hernández, C. F. (2020b). El acto administrativo. Ediciones Ibáñez.

Gómez Aranguren, G. (2004). Derecho administrativo. Ediciones ABC Editores Librería

Gutiérrez Prieto, H. (2001). El análisis económico del derecho: perspectiva para el desarrollo del derecho económico. En Revista de Derecho No. 15 (1-60).

Herrera Robles, A. (2001). El régimen jurídico de las empresas industriales y comerciales del Estado. En Revista de Derecho No. 15. (62-95).

Hernández Quintero, H. A. (2018). Los delitos económicos en la actividad financiera. Ediciones Ibáñez.

Linares Vegas, J. Á. (2001). Curso de derecho comercial. Ediciones Ibáñez.

Madriñán de la Torre (2004). Principios de derecho comercial. Ediciones Temis.

Marín Cortés, F. G. (2008). Público y privado. Ediciones TEMIS.

Marín Vélez, M. (2016). Temas fundamentales del derecho administrativo. Ediciones Ibáñez-Universidad Libre.

Medellín Forero, C. (2013). Lecciones de derecho romano. Ediciones Legis.

Montaña Plata, A. (2010). Fundamentos de derecho administrativo. Ediciones Universidad Externado de Colombia.

Quintana, E. (2004). Ciencia del derecho mercantil. Teoría, doctrina e instituciones. Ediciones Porrúa.

Pinzón Camargo, M. A. (2016). Prácticas para mejorar la regulación en Colombia. En 
Revista de Economía Institucional. (207-227). Ediciones Universidad Externado de Colombia.

Rodríguez Rodríguez, L. (2012). Estructura del poder público en Colombia. Ediciones TEMIS.

Tafur Galvis, Á. (1974). Entidades descentralizadas. Ediciones Rosaristas.

Tafur Galvis, Á. (1996). Estudios de derecho público. Ediciones Ibáñez.

Vidal Perdomo, J. (1966). Derecho administrativo general. Ediciones TEMIS.

Vidal Perdomo, J. (2004). Derecho administrativo. Bogotá: Ediciones Legis-Universidad del Rosario.

Younes Moreno, D. (2016). Curso de derecho administrativo.Ediciones TEMIS.

\section{Normativa}

Presidencia de la República. (1971). Decreto 410 por el cual se expide el Código de Comercio. Consultado desde http://www.secretariasenado.gov.co/senado/ basedoc/codigo_comercio.html

Congreso de la República de Colombia. (1998). Ley 489 por la cual se dictan normas sobre la organización y funcionamiento de las entidades del orden nacional, se expiden las disposiciones, principios y reglas generales para el ejercicio de las atribuciones previstas en los numerales 15 y 16 del Artículo 189 de la Constitución Política y se dictan otras disposiciones. Consultada desde: http://www.secretariasenado.gov.co/ senado/basedoc/ley_0489_1998.html\#1

\section{Providencias}

Corte Constitucional de Colombia. (1996). Sentencia C-253. M.P. Hernando Herrera Vergara. https://www.corteconstitucional.gov.co/relatoria/1996/C-253-96.htm

Corte Constitucional de Colombia. (2003). Sentencia C-150. M.P. Manuel José Cepeda Espinosa. https://www.corteconstitucional.gov.co/relatoria/2003/C-150-03.htm

Corte Constitucional de Colombia. (2009). Sentencia C-034. M.P. Marco Gerardo Monroy Cabra. https://www.corteconstitucional.gov.co/relatoria/2009/C-034-09. htm\#: : :text =C\%2D034\%2D09\%20Corte\%20Constitucional\%20 de\%20 Colombia\&text $=$ La\%20 cosa\%20juzgada\%20 constitucional\%20puede,la\%20 inmutabilidad\%20de\%20la\%20sentencia.\&text=De\%20igual\%20manera\%2C\%20 esta\%20Corporaci\%C3\%B3n, relativo\%20de\%20la\%20cosa\%20juzgada.

Corte Constitucional de Colombia. (1992). Sentencia T-006. M.P. Eduardo Cifuentes Muñoz. https://www.corteconstitucional.gov.co/relatoria/1992/t-006-92.htm 